\title{
Seleção assistida por marcadores para teor de matéria seca e açúcares redutores em tubérculos de batata
}

\author{
Marker assisted selection for dry matter and reducing sugars in potato tubers \\ Leonardo Lopes Bhering ${ }^{\mathrm{I}}$ César Augusto Brasil Pereira Pinto ${ }^{\mathrm{II}}$ \\ Flávio Rodrigo Gandolfi Benites ${ }^{\mathrm{III}}$ Monik Evelin Leite ${ }^{\mathrm{IV}}$ Felipe Lopes da Silva $^{\mathrm{V}}$
}

\section{RESUMO}

A seleção precoce de clones que possuam níveis elevados de matéria seca e baixos teores de açúcares redutores é uma necessidade nos programas de melhoramento para a qualidade de processamento da batata (Solanum tuberosum L.) na forma de palitos fritos ou chips. A seleção precoce tornouse possível com a utilização de marcadores genéticos, visto que permitem a identificação precisa de indivíduos superiores. Assim, procura-se cada vez mais encontrar marcadores capazes de caracterizar tais indivíduos e utilizá-los via seleção assistida. $O$ objetivo deste trabalho foi avaliar a eficiência da seleção assistida, utilizando os marcadores identificados por ANDREU (2004) que estariam associados ao teor de matéria seca e açúcares redutores em tubérculos de batata. Clones provenientes de 20 famílias foram avaliados nas gerações de plântula $(P)$, primeira geração clonal (C1) e segunda geração clonal (C2). As estimativas das correlações simples para os caracteres entre gerações foram significativas, porém, baixas, confirmando a inviabilidade de se efetuar a seleção precoce nas primeiras gerações com base apenas em informações fenotípicas. Os marcadores utilizados forneceram um total de 16 marcas. Pela regressão múltipla stepwise, apenas sete dessas marcas tiveram associação com os caracteres estudados. Além disso, nenhuma marca associada ao teor de matéria seca de tubérculos na geração C1 teve associação significativa na geração C2. Isso também foi observado com o teor de açúcares redutores, o que é um indicativo da interação QTLs x ambientes. A seleção assistida não se mostrou eficiente em relação à fenotípica em nenhum dos casos avaliados, portanto, não sendo útil em uma possível seleção precoce. Esses resultados indicam que tais marcadores não estão próximos aos genes controladores dos caracteres desejados, sendo necessária a identificação de novos marcadores mais associados que possibilitem maior eficiência da seleção assistida.
Palavras-chave: Solanum tuberosum L., seleção precoce, qualidades de tubérculos.

\section{ABSTRACT}

Early generation selection for clones with high content of tuber dry matter and low levels of reducing sugars is required for potato (Solanum tuberosum L.) processing. Selection of superior clones at early generations became possible with the deployment of genetic markers, and can precisely identify the superior individuals. Therefore, it is necessary to identify genetic markers closely linked to genes of interest to do assisted selection. The aim of this research was to evaluate the efficiency of marker assisted selection with genetic markers previously identified by ANDREU (2004), which are assumed to be associated with dry matter and reducing sugars content in potato tubers. Clones from 20 families were evaluated during the seedling generation (S), first clonal generation (C1) and second clonal generation (C2). The estimated coefficients of correlation for all traits among generations were significant, even though of low magnitude, confirming that selection at early generation based only on phenotypic traits is inviable. A total of sixteen bands were amplified using these markers. However, by multiple stepwise regression, only seven of these bands showed association with the evaluated traits. Moreover, no markers associated with dry matter and reducing sugars content in the C1 were significantly associated with these traits in the C2, suggesting the existence of QTLs $x$ environment interactions. The marker assisted selection resulted less efficient than the phenotypic selection in all cases studied, and thus is not recommended for early generation selection of clones for the processing industry. These results suggest that the markers used are not closely linked to the genes controlling the traits most important for processing. Therefore, it is important to identify new markers closely linked with such traits of interest that could improve the efficiency of marker assisted selection.

IEMBRAPA Agroenergia - CNPAE, Parque Estação Biológica - PqEB s/n, 70770-901, Brasília, DF, Brasil. E-mail: leonardo.bhering@embrapa.br

"Departamento de Biologia, Universidade Federal de Lavras (UFLA), CP 3037, 37200-000, Lavras, MG, Brasil. E-mail: cesarbrasil@ufla.br. Autor para correspondência.

IIIEMBRAPA Algodão - póloda Bahia, Luiz Eduardo Magalhães, BA, Brasil. E-mail: frgbenites@yahoo.com.br

IvPrograma de Pós-graduação em Genética e Melhoramneto de Plantas, Departamento de Biologia, UFLA, Lavras, MG, Brasil. Email: monik_leite@yahoo.com.br

VEmpresa de Pesquisa Agropecuária de Minas Gerais (EPAMIG), Centro Tecnológico da Zona da Mata (CTZM), Vila Gianetti, casas 46 e 47, Campus da Universidade Federal de Viçosa, 36571-000, Viçosa, MG, Brasil. E-mail:felipe@epamig.ufv.br 
Key words: Solanum tuberosum L., early generation selection, tuber quality traits.

\section{INTRODUÇÃO}

No Brasil, a principal forma de utilização da batata (Solanum tuberosum L.) é para mesa, enquanto que, em países industrializados, a batata processada representa a maior parte do mercado. Contudo, o panorama nacional tende a mudar em direção à maior utilização de produtos industrializados produzidos a partir da batata. Para o processamento industrial, principalmente na forma de produtos fritos (palitos préfritos ou chips), características como alto teor de matéria seca, baixo teor de açúcares redutores e olhos pouco profundos devem ser consideradas na escolha dos tubérculos. Teores mais elevados de matéria seca conferem maior crocância, enquanto que baixos teores de açúcares redutores possibilitam o desenvolvimento de coloração clara no produto processado. O teor de matéria seca de tubérculos está altamente correlacionado com o peso específico (SCHIPPERS, 1976), que, além de ser um caráter não-destrutivo, é de fácil avaliação.

Para atender a demanda de cultivares nacionais de batata que satisfaçam os padrões para o processamento industrial, os programas de melhoramento genético têm dado prioridade ao desenvolvimento de novas cultivares mais adaptadas, produtivas e de alta qualidade culinária. Esses programas iniciam com o cruzamento entre genitores e produção de milhares de clones, que devem ser avaliados para a seleção dos mais promissores. No início do programa, o melhorista se depara com elevado número de clones e pequeno número de tubérculossemente de cada um deles. Assim, as avaliações iniciais são pouco precisas. À medida que o número de clones vai se reduzindo pela seleção e o número de tubérculos-semente de cada clone vai aumentando, as avaliações passam a ser mais precisas, permitindo que a seleção seja mais rigorosa e eficiente. A seleção precoce é, portanto, uma necessidade nos programas de melhoramento de batata, embora a eficiência seja questionável (MARIS, 1988; NEELE \& LOUWES, 1989).

Com o advento dos marcadores moleculares, abriu-se a possibilidade de incrementar a precisão experimental e, conseqüentemente, aumentar os ganhos com a seleção. Os marcadores permitem a seleção de indivíduos com base no seu genótipo, sendo os ganhos teoricamente superiores aos obtidos com a seleção fenotípica. Os marcadores poderiam ainda auxiliar na identificação precoce de clones superiores, reduzindo o número de indivíduos a serem avaliados posteriormente em campo.
O objetivo deste trabalho foi avaliar os marcadores identificados por ANDREU (2004) e a eficiência destes na seleção assistida por marcadores (SAM) como uma ferramenta útil na seleção precoce para o teor de matéria seca e açúcares redutores, caracteres importantes para o processamento da batata na forma de produtos fritos.

\section{MATERIAL E MÉTODOS}

Em 2004, foram semeadas sementes botânicas de 20 famílias clonais, oriundas de cruzamentos entre clones pertencentes ao Programa de Melhoramento Genético da Batata, da UFLA. Após 35 dias, as mudas foram transplantadas para vasos contendo substrato organo-mineral e mantidas em casa de vegetação até completarem o ciclo (geração S). Na colheita, um tubérculo de cada plântula foi avaliado para peso específico de tubérculos (PET) por meio de soluções salinas, conforme metodologia descrita por MONTALDO (1984), com algumas adaptações.

O experimento da primeira geração clonal (C1) foi instalado em área de produção comercial de batata, localizada em Carrancas, Minas Gerais (MG), no período de fevereiro a maio de 2005. O delineamento experimental foi blocos casualizados, com 20 tratamentos (famílias) e três testemunhas (Ágata, Asterix e Atlantic). Cada família foi representada por 30 plantas (clones diferentes), distribuídas em três repetições de 10 plantas (clones), no espaçamento $0,50 \times 0,80 \mathrm{~m}$. Foram avaliados a produção total (g planta-1) e o peso específico dos tubérculos (PET) pela expressão: PET = massa no ar/ (massa no ar - massa na água), obtidos em balança hidrostática, e a porcentagem de açúcares redutores pela metodologia DNS (MILLER, 1959).

Após a colheita, foram tomados, aleatoriamente, 200 clones, 10 de cada família, para serem avaliados em experimento com repetições e formarem a segunda geração clonal (C2). O experimento foi instalado em campo de produção comercial, no município de São João da Mata, MG, no período de setembro de 2005 a janeiro de 2006, sendo constituído de 200 clones e as mesmas testemunhas utilizadas na $\mathrm{C} 1$. O delineamento foi de blocos casualizados, com três repetições e duas plantas por parcela, espaçadas de 0,30 x 0,80m. Foram avaliados a produção de tubérculos (g planta ${ }^{-1}$ ), o PET determinado em balança hidrostática, a porcentagem de tubérculos graúdos (massa de tubérculos com diâmetro $>45 \mathrm{~mm} /$ massa total de tubérculos) x 100; e a nota de coloração desenvolvida pelos palitos de cerca de $1 \mathrm{~cm}$ de seção, após a fritura por cinco minutos a $180^{\circ} \mathrm{C}$ em gordura hidrogenada. A coloração foi avaliada por meio da tabela da Snack Food Association (EUA). 
Para a extração de isoenzimas, foi utilizado homogenado de folhas jovens coletadas antes da floração, aos 35 dias após o plantio. Foram utilizados 300mg de tecido foliar de cada amostra, 0,5mg de polivilpirrolidona (PVP) e $1 \mathrm{~mL}$ de solução tampão $\mathrm{n}^{\circ} 1$ de ALFENAS et al. (1998). A eletroforese foi conduzida em gel de poliacrilamida, sendo de $4,5 \%$ o gel de concentração e 7,5\% o gel de separação. Na corrida eletroforética, usou-se corrente de $10 \mathrm{~mA}$ para cada gel e tempo total de três horas a $4^{\circ} \mathrm{C}$. Foram usados três sistemas enzimáticos, a-esterase (EST), peroxidase (PO) e malato desidrogenase (MDH), identificados por ANDREU (2004) como provavelmente ligados ao PET. As revelações foram feitas de acordo com a metodologia de ALFENAS et al. (1998) e procedeu-se à interpretação dos zimogramas.

A extração de DNA foi realizada seguindo o procedimento modificado de ROGERS \& BENDICH (1988). As reações de RAPD e PCR foram identificadas com os iniciadores identificados por ANDREU (2004) como relacionados com caracteres importantes para o processamento industrial da batata. Foram utilizados dois iniciadores de RAPD (OPA-10 e OPG-05) e um par de iniciadores de PCR especialmente desenhados para a identificação do gene da amido sintetase (SS). Os fragmentos obtidos foram separados em gel de agarose na concentração de 2,5\%. A eletroforese foi conduzida em tampão TBE $1 \mathrm{X}$ à voltagem constante de $100 \mathrm{~V}$, durante um período variável de três horas e meia a quatro horas. A visualização do gel foi efetuada sob luz UV e registrada em computador.

Foi construída uma matriz de zeros (ausência) e uns (presença) de bandas, sendo cada banda considerada um caráter único. Para eliminação de marcas não-informativas, utilizou-se o procedimento de eliminação de variáveis no módulo stepwise do software GQMOL, versão 2005.6.1 (CRUZ \& SCHUSTER, 2004). Desse modo, um marcador previamente adicionado ao modelo pode ser eliminado em um passo subseqüente por ter se tornado redundante devido à inclusão de outro(s) marcador (es). Para isso foi considerado o nível de significância de $10 \%$.

Para a seleção, empregou-se o procedimento "seleção assistida” do GQMOL, sendo obtido um escore com o somatório das marcas que fosse relativo aos marcadores selecionados pela regressão múltipla no módulo stepwise, associados a cada caráter avaliado. Foram selecionados os indivíduos com maiores escores e destes foi estimado o diferencial de seleção ( $d s$ ) em relação à média da população original. $\mathrm{O} d s$ desses indivíduos selecionados foi comparado com o ds dos indivíduos fenotipicamente superiores e, a partir daí, observou-se qual o método de seleção foi super em relação à média original.

\section{RESULTADOS E DISCUSSÃO}

A média do PET da geração plântula foi de 1,0851, que é superior ao valor encontrado por AMARO et al. (2003) em plântulas cultivadas em substrato organo-mineral, em casa de vegetação. Aproximadamente 65,2\% das plântulas apresentaram PET igual ou superior a 1,080.

Das 20 famílias avaliadas, 14 (70\%) apresentaram médias de PET iguais ou superiores a 1,0800 (21,7\% de matéria seca) que, segundo GOULD (1988), são valores desejáveis para o processamento industrial. Essa informação é importante na seleção precoce, pois indica quais famílias possuem maior potencial de produção de clones superiores para tal característica. A seleção de famílias é uma metodologia que tem sido proposta para reduzir custos e aumentar a eficiência dos programas de melhoramento da batata, conforme relatado por NEELE \& LOUWES (1989), SIMMONDS (1996), GOPAL (1997), AMARO et al. (2003).

Na primeira geração clonal, foram detectadas diferenças significativas entre as famílias para os três caracteres avaliados. A média do PET $(1,064)$ foi inferior à média observada na geração plântula $(1,0851)$ provavelmente devido à influência ambiental entre a condição de campo (C1) e em vasos (S). Isso fica evidenciado pelo comportamento das testemunhas no experimento de campo que apresentaram PET de 1,041 (Ágata), 1,058 (Asterix) e 1,065 (Atlantic). Em inúmeros experimentos conduzidos em condições semelhantes pelo programa de melhoramento da UFLA, essas cultivares normalmente apresentam PET médio de 1,055 (Ágata), 1,076 (Asterix) e 1,081 (Atlantic). Aproximadamente $50 \%$ dos clones C1 tiveram desempenho superior a todas as testemunhas.

As estimativas das herdabilidades no sentido amplo foram moderadamente altas para os três caracteres (Tabela 1 ). O teor de açúcares redutores apresentou a maior estimativa de herdabilidade e intervalo de confiança mais estreito que os demais caracteres. Além disso, esse caráter também foi o que apresentou a maior estimativa da relação $\mathrm{CV}_{\mathrm{G}} / \mathrm{CV}$, indicando que a seleção deve ser mais eficiente do que a produção de tubérculos e o PET. A média para o teor de açúcares redutores foi de $0,284 \%$, valor inferior ao recomendado por STOREY \& DAVIES (1992) para a obtenção de produtos fritos com coloração aceitável. Porém, segundo MELO (1999) e PEREIRA (2000), os valores ideais para a indústria seriam inferiores a $0,2 \%$. 
Tabela 1 - Estimativas dos parâmetros genético-estatísticos para a produção de tubérculos, peso específico de tubérculos, teor de açúcares redutores e porcentagem de tubérculos graúdos na primeira geração colonal (C1) e na segunda geração clonal (C2).

\begin{tabular}{|c|c|c|c|c|c|c|}
\hline \multirow[t]{2}{*}{ Parâmetro } & \multicolumn{2}{|c|}{ Produção de tubérculos (g planta-1 ) } & \multicolumn{2}{|c|}{ Peso específico dos tubérculos } & \multirow{2}{*}{$\begin{array}{c}\begin{array}{c}\text { Açúcares redutores } \\
(\%)\end{array} \\
\text { C1 }\end{array}$} & \multirow{2}{*}{$\begin{array}{c}\begin{array}{c}\text { Tubérculos graúdos } \\
(\%)\end{array} \\
\text { C2 }\end{array}$} \\
\hline & C1 & $\mathrm{C} 2$ & C1 & $\mathrm{C} 2$ & & \\
\hline Média & 584,1 & 905,6 & 1,0636 & 1,0738 & 0,284 & 64,8 \\
\hline $\mathrm{CV}_{\mathrm{e}}(\%)$ & 20,2 & 51,9 & 0,8 & 0,9 & 17,3 & 27,3 \\
\hline $\mathrm{CV}_{\mathrm{G}}(\%)$ & 17,1 & 21,4 & 0,6 & 0,80 & 22,1 & 18,1 \\
\hline $\mathrm{CV}_{\mathrm{G}} / \mathrm{CV}_{\mathrm{e}}$ & 0,85 & 0,41 & 0,76 & 0,85 & 1,28 & 0,66 \\
\hline$h_{a}^{2}(\%)$ & 69,39 & 33,78 & 63,43 & 68,46 & 76,57 & 56,82 \\
\hline IC da $h^{2}{ }_{a}$ & $26,0-85,0$ & $15,1-47,6$ & $14,1-82,6$ & $61,0-76,0$ & $69,0-82,3$ & 44,0 a 65,5 \\
\hline$\sigma_{G}^{2}$ & 10002,99 & 37511,78 & $3,8 \times 10^{-5}$ & $7,3 \cdot 10^{-5}$ & $3,95 \cdot 10^{-3}$ & 137,00 \\
\hline
\end{tabular}

$\mathrm{CV}_{\mathrm{e}}$ : coeficiente de variação ambiental; $\mathrm{CV}_{\mathrm{G}}$ : coeficiente de variação genética; $\sigma_{\mathrm{G}}^{2}$ : variância genética, $\mathrm{h}_{\mathrm{a}}^{2}$ : herdabilidade no sentido amplo; IC: intervalo de confiança da $h_{a}^{2}$.

$\mathrm{Na}$ segunda geração clonal, foram detectadas diferenças significativas entre os clones para todos os caracteres avaliados. A média dos clones para a produção de tubérculos foi de 905,0g planta-1 enquanto as médias das testemunhas foram de $1.141 \mathrm{~g}$ planta $^{-1}$ para a cultivar 'Asterix', de 433,3g planta $^{-1}$ para a cultivar Ágata e 1.029g planta $^{-1}$ para a cultivar 'Atlantic'. Quarenta e seis clones (23\% da população) apresentaram produção de tubérculos superior à média da testemunha mais produtiva (Asterix). A porcentagem média de tubérculos graúdos foi ligeiramente inferior à média das testemunhas. Já para o PET, a média dos clones foi de 1,074 (aproximadamente 20,3\% de matéria seca), superando as testemunhas, que apresentaram médias de 1,043 (Ágata), 1,062 (Asterix) e 1,068 (Atlantic). Cento e trinta e seis clones (68,3\% da população) se destacaram por apresentar PET superior à da cultivar 'Atlantic', que é a principal cultivar utilizada industrialmente no Brasil para a produção de chips.

Os coeficientes de herdabilidade foram baixos a moderados e inferiores às estimativas da geração C1. Provavelmente esses resultados se devem ao tipo de parcela utilizada em cada geração. Enquanto que na C1 foram avaliadas famílias em parcelas de 10 plantas, na C2 foram avaliados os clones individuais em parcelas de duas plantas.

Em geral, os coeficientes de correlação foram baixos, embora a maioria tenha sido significativo, com exceção da cor de chips entre C1 x C2 (Tabela 2). Diversos fatores podem ter contribuído para as baixas correlações. A geração S foi cultivada em vasos contendo substrato organo-mineral em casa de vegetação, já as gerações C1 e C2 foram cultivadas em campos comerciais de produção de batata. Além disso, à medida que as gerações vão avançando, há uma tendência de aumento das correlações, pelo fato de o comportamento dessas gerações avançadas ser semelhante e, principalmente, deixam de existir grandes diferenças em tamanho e fisiologia da batata-semente. Por fim, nas gerações C1 e C2, o PET foi obtido em balança hidrostática, enquanto que na geração $\mathrm{S}$ foi obtido por meio de soluções salinas.

Para a cor de chips, a correlação entre as gerações C1 e C2 foi não-significativa, o pode ser devido ao diferente modo de estimar os teores de açúcares redutores nessas gerações. Na geração C1, foi obtida a porcentagem de açúcares redutores pela metodologia DNS. Na C2, a avaliação foi indireta, pela coloração exibida pelo clone após a fritura. Genótipos que são indicados para o processamento na forma de chips devem apresentar-se dentro de um escore aceitável já nas primeiras gerações clonais (THILL \& PELOQUIN, 1995). Um dos principais fatores que deve ter contribuído para limitar os valores de correlações nessas gerações foi a variação não-genética entre os

Tabela 2 - Coeficientes de correlação de Pearson entre as gerações de seleção para a produção de tubérculos, peso específico de tubérculos (PET) e a coloração dos chips.

\begin{tabular}{lccc}
\hline Caracteres & S x C1 & S x C2 & C1 x C2 \\
\hline Produção $\left(\right.$ g planta $^{-1}$ ) & & & $0,16^{*}$ \\
PET & $0,22^{* *}$ & $0,26 * *$ & $0,42^{* *}$ \\
$\begin{array}{l}\text { Cor de chips/ teor de açúcares } \\
\text { redutores }\end{array}$ & & & $0,12 \mathrm{~ns}$ \\
\hline
\end{tabular}

*, **: significativo a $5 \%$ e $1 \%$ de probabilidade, pelo teste $\mathrm{t}$, respectivamente; ns: não-significativo pelo teste t.

Ciência Rural, v.39, n.1, jan-fev, 2009. 
clones. Esta se deve, dentre outros fatores, ao número limitado de plantas e à não utilização de repetições na C-1, devido à pouca disponibilidade de tubérculos. Resultado semelhante foi observado por AMARO et al. (2003), estudando as correlações entre as gerações S, C1 e C2 para o PET.

Os resultados apresentados confirmam a dificuldade de se praticar a seleção nas primeiras gerações de um programa de melhoramento de batata, visto que a disponibilidade de batata-semente é limitada e o número de genótipos é elevado. Como conseqüência, ocorre a redução na precisão das avaliações, o que compromete a eficiência das seleções nessas situações.

Dos marcadores genéticos utilizados, foi identificado um total de 16 bandas polimórficas, sendo quatro pertencentes ao iniciador OPA-10, uma referente ao iniciador de PCR (SS) e 11 referentes aos três sistemas enzimáticos, sendo três identificadas para o sistema $\alpha$-esterase, quatro para peroxidase (PO) e quatro para malato desidrogenase (MDH). Os resultados da análise de regressão múltipla stepwise das 16 bandas polimórficas indicaram que três bandas isoenzimáticas mostraram associação significativa com o PET. Nenhuma marca foi significativa para o PET, determinada em solução salina na geração S. Para a cor de chips, a análise de regressão indicou uma associação significativa de um loco de RAPD e seis bandas isoenzimáticas. O loco polimórfico do iniciador de PCR e as bandas polimórficas oriundas do sistema isoenzimático $\alpha$-esterase não tiveram associação significativa com nenhum dos caracteres avaliados neste trabalho.

Das 16 bandas avaliadas, apenas sete mostraram-se relacionadas significativamente com as características importantes para o processamento industrial da batata, sendo portanto as utilizadas na seleção assistida (Tabela 3). Verifica-se ainda que, para a mesma característica, não foi observada uma mesma marca associada significativamente. Isso é um forte indicativo da existência da interação QTLs x ambientes, uma vez que o PET e o teor de açúcares redutores são controlados por um grande número de genes de pequeno efeito sobre o caráter (poligenes). Na SAM, foram selecionados os indivíduos que apresentaram as marcas para todos os marcadores significativos para cada característica avaliada. Em seguida, comparou-se a média dos indivíduos selecionados com a presença das bandas e a média dos indivíduos selecionados fenotipicamente.
Tabela 3 - Marcadores relacionados significativamente com o peso específico de tubérculos (PET) e teor de açúcares redutores (TAR) nas gerações plântula (S), na primeira geração clonal (C1) e na segunda geração clonal (C2).

\begin{tabular}{lcc}
\hline Marca & Caráter & Gerações \\
\hline Nenhuma & PET & S \\
PO-4 & PET & C1 \\
MDH-2 & PET & C1 \\
PO-3 & PET & C2 \\
MDH-4 & TAR & C1 \\
PO-4 & TAR & C1 \\
OPA 10-2 & TAR & C1 \\
PO-2 & TAR & C1 \\
MDH-2 & TAR & C1 \\
PO-1 & Nota de Fritura & C2 \\
PO-3 & Nota de Fritura & C2 \\
\hline
\end{tabular}

Para o PET da geração C1, dos 200 indivíduos avaliados, 122 apresentaram escore igual a dois, por apresentarem a banda na marca MDH-2 e PO4. Se fosse realizada uma seleção considerando apenas a presença das marcas, a média da população selecionada seria inferior à média original da população. Tal situação não é desejável, pois estaria indo contra a pressão feita na seleção necessária ao melhoramento, que tem como objetivo aumentar os valores do PET. Nesse caso, a média dos indivíduos selecionados fenotipicamente foi $0,74 \%$ superior à média da SAM, representando uma diferença de 1,6\% de matéria seca nos tubérculos (Figura 1A).

Para o PET na segunda geração clonal (C2), apenas uma marca foi significativa. Dos 200 indivíduos avaliados, 184 apresentam essa marca (PO-3), que se mostrou pouco polimórfica. A média dos 200 indivíduos da população foi de 1,074. Comparando-os com os clones selecionados fenotipicamente verifica-se novamente que a seleção fenotípica propiciaria os melhores ganhos (Figura 1B). Na segunda geração clonal, a herdabilidade foi de 0,68 , e a seleção fenotípica proporcionaria um ganho com a seleção de $0,087 \%$. Por outro lado, o ganho de seleção obtido com a SAM, considerando a herdabilidade da marca de $100 \%$, seria de apenas 0,0364\%. Esse valor é 2,4 vezes inferior ao obtido pela seleção fenotípica. A diferença entre as médias dos selecionados em cada situação corresponde a 0,2\% de matéria seca nos tubérculos.

A porcentagem de açúcares redutores foi a característica que apresentou maior número de marcas associadas significativamente (cinco ao todo). A média original de todos os indivíduos da população foi de

Ciência Rural, v.39, n.1, jan-fev, 2009. 

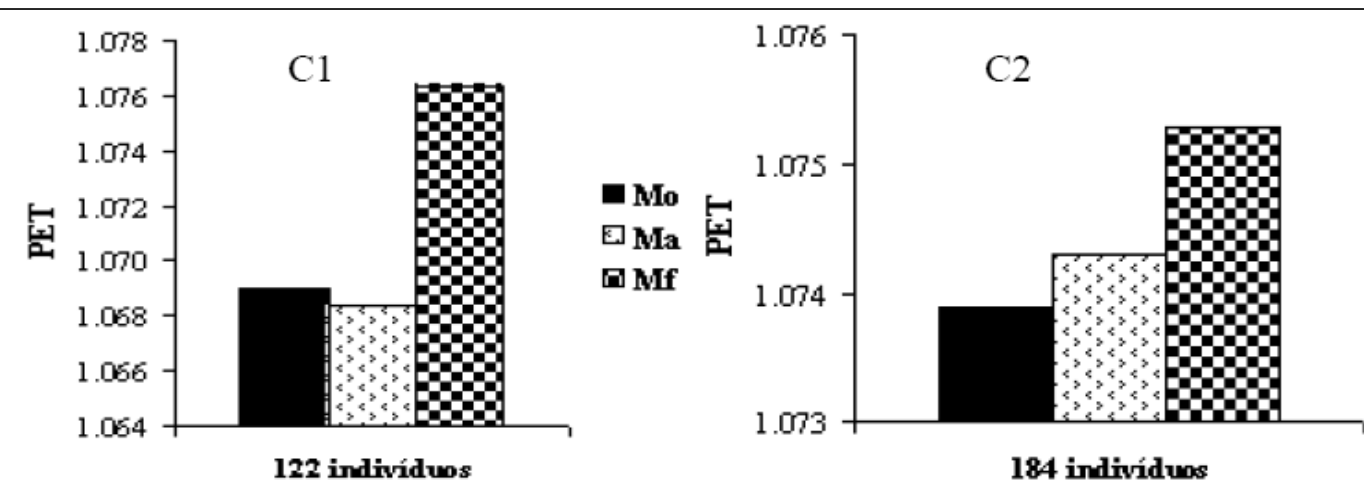

Mo

미

点 Mf

Figura 1 - Variação das médias para peso específico de tubérculos dos indivíduos selecionados na primeira (C1) e na segunda (C2) geração clonal pelas seleções fenotípica (Mf) e assistida (Ma) e seu comportamento em relação à média geral do experimento (Mo).

0,284, enquanto que a média dos 41 indivíduos selecionados com base na SAM foi de 0,302. Já a média de indivíduos selecionados fenotipicamente foi de 0,192 . Ficou evidenciado que a SAM propiciou aumento no teor de açúcares redutores, enquanto que a seleção fenotípica selecionou os indivíduos com menores teores. Isso mostra que os marcadores, nesse caso, não estão contribuindo favoravelmente para a seleção, pois maiores valores dos açúcares redutores significam maior escurecimento após a fritura. (Figura 2A).

Para a coloração dos chips, foi observado resultado similar ao obtido para a porcentagem de açúcares redutores nos tubérculos. Ao considerar todos os indivíduos que apresentaram as bandas para os dois marcadores, foram selecionados 121 indivíduos cuja média foi superior à média da população original (Figura 2B).

\section{CONCLUSÕES}

Dos marcadores avaliados, o iniciador de PCR e sistema isoenzimático $\alpha$-esterase não se mostraram significativamente relacionados com nenhum dos caracteres importantes para o processamento. Observou-se uma forte interação QTLs $\mathrm{x}$ ambientes tanto para a matéria seca de tubérculos, quanto para o teor de açúcares redutores.

A seleção assistida não foi eficiente em nenhuma das gerações analisadas. Portanto, é necessária a detecção de novos marcadores que estejam mais próximos ou que flanqueiam esses QTL’s para que a eficiência da seleção assistida seja aumentada.

\section{AGRADECIMENTO}

À Comissão de Aperfeiçoamento de Pessoal de Nível Superior (CAPES), pela bolsa de pós-graduação concedida a L. L. Bhering.

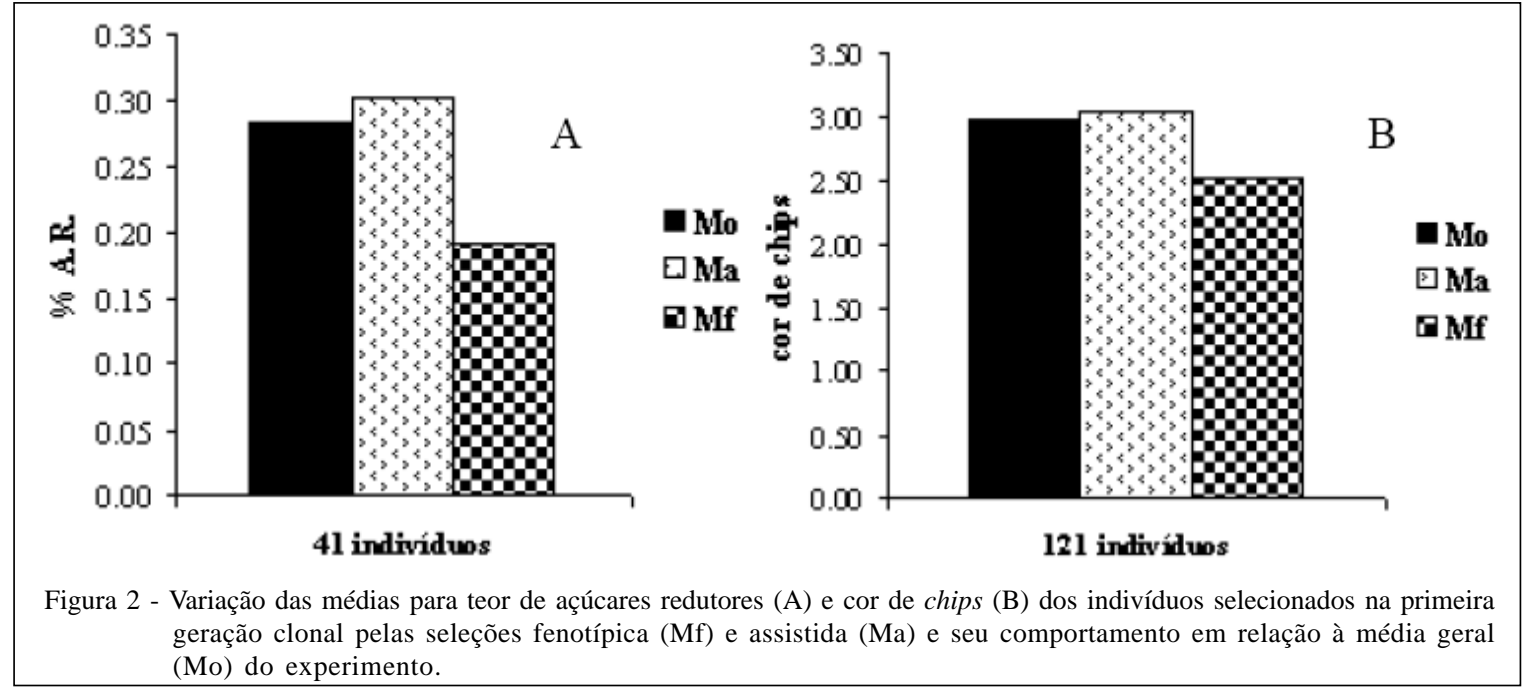

Ciência Rural, v.39, n.1, jan-fev, 2009. 


\section{REFERÊNCIAS}

ALFENAS, C.A. et al. Eletroforese de proteínas e isoenzimas afins: fundamentos e aplicações em plantas e microorganismos. Viçosa: UFV, 1998. 574p.

AMARO, G.B. et al. Seleção precoce de clones de batata para caracteres dos tubérculos. Ciência e Agrotecnologia, v.27, n.3, p.585-589, 2003.

ANDREU, M.A. Seleção de clones e identificação de marcadores genéticos para qualidade de processamento da batata. 2004. 94f. Dissertação (Mestrado em Genética e Melhoramento de Plantas) - Universidade Federal de Lavras.

CRUZ, C.D.; SCHUSTER, I. GQMOL - Aplicativo computacional para análise de dados moleculares e suas associações com caracteres quantitativos, versão 2005 . 6.1. Viçosa UFV, 2004.

GOULD, W.A. Quality of potatoes for chip manufacture. In: SYMPOSIUM POTATO, 1988, Fort Collins. Proceedings... Fort Collins: The Potato Association of America, 1988. p.1121.

GOPAL, J. Progeny selection for agronomic characters in early generations of potato breeding programme. Theoretical and Applied Genetics, v.95, n.3, p.307-311, 1997.

MARIS, B. Correlations within and between characters between and within generations as a measure for the early generation selection in potato breeding. Euphytica, v.37, n.3, p.205224, 1988.

MELO, P.E. Cultivares de batata potencialmente úteis para processamento na forma de fritura no Brasil e manejo para obtenção de tubérculos adequados. Informe Agropecuário, v.20, n.197, p.112-119, 1999.

MILLER, G.L. Use of dinitrossalicylic acid reagent for determination of reducing sugar. Analytical Chemistry, Washington, v.31, n.3, p.426-428, 1959.

MONTALDO, A. Cultivo y mejoramento de la papa. San José: IICA, 1984. 676p.

NEELE, A.E.F.; LOUWES, K.M. Early selection for chip quality and dry matter content in potato seedling populations in greenhouse or screenhouse. Potato Research, v.32, n.2, p.293300, 1989.

PEREIRA, A.S. Melhoramento genético da batata. In: SIMPÓSIO DE ATUALIZAÇÃO E MELHORAMENTO DE PLANTAS, 4., 2000, Lavras. Anais... Lavras: UFLA, 2000. p.41-50.

ROGERS, S.O.; BENDICH, A.J. Extration of DNA from plant tissues. Plant Molecular Biology Manual A6, v.6, p.1-10, 1988.

SCHIPPERS, P.A. The relationship between specific gravity and percentage of dry matter in potato tubers. American Potato Journal, v.53, n.4, p.111-112, 1976

SIMMONDS, N.W. Family selection in plant breeding Euphytica, v.90, n.2, p.201-208, 1996.

STOREY, R.M.J.; DAVIES, H.V. Tuber quality. In: HARRIS, P.M. (Ed.). The potato crop. 2.ed. London: Chapman and Hall, 1992. p.507-569.

THILL, C.A.; PELOQUIN, S.J. A breeding method for accelerated development of cold chipping clones in potato. Euphytica, v.84, n.1, p.73-80, 1995. 